\title{
Pancreatic Involvement by Plasma Cell Neoplasms
}

\author{
Rodrigo Lopes da Silva
}

Published online: 16 August 2011

(C) Springer Science+Business Media, LLC 2011

\begin{abstract}
Introduction Pancreatic involvement by plasma cell neoplasms is an extremely rare event, with only 50 cases described in the literature. They can present as a primary solitary extramedullary plasmacytoma or plasmacytoma secondary to a plasma cell myeloma. Clinical manifestations are due to the presence of a pancreatic mass usually in the pancreas head, which causes extra-biliary obstruction and abdominal pain.

Methods Abdominal imaging including CT scan or endoscopic ultrasound with fine-needle aspiration tissue sampling is essential for the initial diagnostic procedure. However, immunohistochemical analysis of the biopsy specimen or flow cytometry of the aspirated material is crucial to prove the monoclonality and the final diagnosis of a plasma cell neoplasm.

Discussion Management of these situations include radiotherapy, chemotherapy, surgery or combined therapy. Novel medications including the immunomodulatory drugs or the proteasome inhibitors followed by consolidation with intensive chemotherapy and haematopoietic stem cell transplantation are nowadays used as upfront treatment in the cases associated to a plasma cell myeloma.

Conclusion Despite the rarity, plasma cell neoplasms should be considered in the differential diagnosis of obstructive jaundice and pancreatic neoplasms since they are potentially treatable situations.
\end{abstract}

R. Lopes da Silva $(\square)$

Hospital Santo António dos Capuchos-CHLC,

Alameda Santo António dos Capuchos,

1169-050 Lisbon, Portugal

e-mail: ronolosi@gmail.com
Keywords Pancreas · Plasma cell neoplasms .

Extramedullary plasmacytomas $\cdot$ Plasma cell myeloma .

Obstructive jaundice

\section{Introduction}

Pancreatic involvement in haematologic malignancies is quite an uncommon event. Whilst primary lymphomas of this organ are rare with about 150 cases reported so far [1], on the other hand, plasma cell neoplasms (PCN) are even more uncommon in this organ. PCN are clonal diseases of terminally differentiated $\mathrm{B}$ cells that secret a monoclonal immunoglobulin also called paraprotein or M-protein. The spectrum of PCN encompasses various entities: monoclonal gammopathy of undetermined significance (MGUS); plasma cell myeloma (PCM) variants smoldering, symptomatic, non-secretory and plasma cell leukaemia; plasmacytoma (solitary plasmacytoma of bone, extraosseous/extramedullary plasmacytoma); immunoglobulin deposition diseases (primary amyloidosis, systemic light and heavy-chain deposition diseases); and osteosclerotic myeloma/POEMS syndrome) [2]. Among those, only primary extramedullary plasmacytoma (EMP) and secondary plasmacytoma due to a PCM have been found to affect the pancreas and cause relevant disease. Primary amyloidosis is caused by a plasma cell or a lymphoplasmacytic neoplasm that secretes intact or fragments of abnormal immunoglobulin light chain or, rarely, heavy chains which accumulate in many tissues in the form of AL amyloid. Although amyloid deposits in pancreatic islets occur in systemic AL amyloidosis, they do not disturb the pancreatic function, whilst other types of amyloid proteins not related to a PCN, namely amylin (islet amyloid polypeptide), are responsible for the pathogenesis of type II diabetes mellitus [3, 4]. 
Osteosclerotic myeloma/POEMS syndrome is a plasma cell neoplasm characterized by fibrosis and osteosclerotic changes in bone trabecula and lymph node, and is component of a broader syndrome that includes polyneuropathy, organomegaly, endocrinopathy, monoclonal gammopathy and skin changes. The endocrinopathy spectrum includes hyperglycaemia and blood glucose intolerance that is not related to a direct pancreatic endocrine damage or dysfunction from a PCN but to the imbalance of proinflammatory cytokines, namely the vascular endothelial growth factor [5]. Since only primary and secondary plasmacytomas have been found to cause relevant abdominal and pancreatic clinical manifestations, focus will be given to these two entities. Primary EMPs are localized plasma cell neoplasms arising in tissues other than the bone and constitute $3-5 \%$ of all PCN, with a strong male predominance $(2 / 3)$ and median age at diagnosis of 55 years (10 years younger than in plasma cell myeloma patients). About $80 \%$ of primary EMP affect the upper respiratory tract (oropharynx, nasopharynx, sinuses, larynx) and the remaining occurring in diverse anatomic sites including lymph nodes, bladder, central nervous system, breast, thyroid, testis, parotid, skin and gastrointestinal tract (stomach, small intestine, colon, liver and pancreas) [6]. PCM accounts for approximately $1 \%$ of all malignancies tumours and $10-15 \%$ of haematopoietic neoplasms. It is more common in men than in women $(1.4: 1)$ and has median age of presentation of about 65 years, but in uncommon cases, it can occur in the second decade of life $[7,8]$. It can be asymptomatic or manifest in aggressive form, and the manifestations are related to the deposition of abnormal immunoglobulin chains in the tissues. Bone marrow involvement is typically present especially in areas of active haematopoiesis. Lytic bone lesions and focal tumoral masses (secondary plasmacytomas) also occur, and extramedullary disease is associated with advanced-stage disease. It is thought that chronic antigenic stimulation from infection, toxins, chronic disease or radiation may predispose for an increased incidence of PCM; however, most patients do not have an identifiable or explainable cause.

\section{Diagnostic Criteria}

It is very important to know whether a pancreatic mass known to be a plasmacytoma is just a primary EMP or is secondary to a PCM because the therapeutic strategies are different, being more aggressive in the latter case due to the required combination of diverse modalities of treatments, whilst EMP can often be cured with local radiation only. To facilitate this distinction, diagnostic criteria for primary EMP and secondary plasmacytomas due to PCM have been proposed $[2,9]$
- Primary EMP diagnostic criteria [2]

1. Absence of M-protein in serum and/or urine

2. More than one localized area of extramedullary tumour of clonal plasma cells that may be recurrent

3. Normal bone marrow

4. No abnormalities in skeletal survey or MRI

5. No any evidence of organ or tissue impairment

- Secondary EMP diagnostic criteria [9]

1. Presence of M-protein in serum or urine (any level)

2. Presence of bone marrow clonal plasma cell or plasmacytoma

3. Manifestations of end-organ damage including anaemia, hypercalcemia, lytic bone lesions, renal insufficiency, hyperviscosity, amyloidosis or recurrent infections

Of particular relevance to underscore is that almost $50 \%$ of patients with primary EMP have small levels of detectable M-protein in the serum or urine that generally disappear after therapy institution. Persistence of M-protein after treatment may indicate an underlying MGUS or the presence of multiple focal lesions often secondary to an evolving PCM.

\section{Incidence}

Pancreatic involvement by $\mathrm{PCN}$ is extremely rare, comprising $<0.1 \%$ of all pancreatic masses. The diagnosis was often made postmortem with an incidence rate of $2.3 \%$ based on autopsy studies, but with the development of more sophisticated imaging techniques, the diagnosis is nowadays made when the patient is still alive, by image-guided biopsy/fine-needle aspiration followed by immunohistochemical or flow cytometry characterization of the specimen. Since the first description in 1947, only 50 cases of primary EMP or plasmacytomas secondary to PCM have been reported so far in the literature [10-58]. A summary of all the reported cases including patient data, type of disease, manifestations and treatment is depicted below (Tables 1 and 2).

\section{Location of the Pancreatic Lesions}

About $80 \%$ of pancreatic EMPs are located in the head of the pancreas, whilst the remaining $20 \%$ are found in the body and the tail of the organ. Most are single lesions; in some cases, two or more concurrent lesions may occur, and even more rarely, the lesion has its epicentre in another abdominal organ but is large enough to affect the pancreas too, mainly the pancreatic tail [32, 41, 42] (Fig. 1a, b). 
Table 1 Patients' characteristics, type of disease, pancreatic location of the mass and lesions in other anatomic sites

\begin{tabular}{|c|c|c|c|c|c|}
\hline Cases & Age (years) & Gender & Type of plasmacytoma & Pancreatic site & Other site(s) \\
\hline Hefferman (1947) & NA & NA & NA & Head & Duodenum \\
\hline Richards et al. (1958) & NA & NA & NA & Head & NA \\
\hline Doutre et al. (1976) & NA & NA & NA & Head & NA \\
\hline Simon et al. (1978) & 68 & $\mathrm{M}$ & Secondary & Head & Lung, bronchi \\
\hline Rice et al. (1981) & 54 & M & Secondary & Head & None \\
\hline Bell et al. (1982) & 88 & M & Secondary & Head/body & Lymph nodes, liver \\
\hline Twomey et al. (1983) & 58 & $\mathrm{~F}$ & Primary & Head & Kidneys \\
\hline Borgia et al. (1984) & 77 & M & Secondary & Head & None \\
\hline Helenon et al. (1984) & 60 & $\mathrm{~F}$ & Secondary & Head & None \\
\hline Jaubert et al. (1985) & 75 & $\mathrm{~F}$ & Primary & Head & None \\
\hline Gorg et al. (1985) & 61 & M & Primary & Head & Pleura \\
\hline Mitchell et al. (1985) & 69 & M & Secondary & Head & None \\
\hline Speelberg et al. (1985) & 57 & $\mathrm{~F}$ & Secondary & Head & None \\
\hline Zafaranloo et al. (1986) & 67 & M & Secondary & Head & None \\
\hline Scheinman et al. (1987) & 29 & $\mathrm{~F}$ & Primary & Head/body/tail & Maxillary sinus \\
\hline Akiyama et al. (1988) & 59 & $\mathrm{~F}$ & Primary & Head & Abdominal \\
\hline Fukuya et al. (1989) & 48 & M & Primary & Head & Epipharynx \\
\hline Wilson et al. (1989) & 52 & $\mathrm{~F}$ & Secondary & Head & Pelvic \\
\hline Brichon et al. (1989) & NA & NA & NA & NA & NA \\
\hline Hamamoto et al. (1990) & 63 & M & Secondary & Head & Pleura \\
\hline Fischer et al. (1991) & 45 & M & Secondary & Head & None \\
\hline Davidson et al. (1993) & NA & NA & NA & NA & NA \\
\hline Olson et al. (1993) & 65 & M & Secondary & Head & None \\
\hline Fautrel et al. (1993) & 58 & M & Primary & Head & Liver \\
\hline Tanaka et al. (1993) & 46 & M & Primary & Tail & Retroperitoneal space, spleen, stomach, intestine, kidney \\
\hline \multirow[t]{2}{*}{ Dodd et al. (1994) } & 55 & $\mathrm{~F}$ & Secondary & Head & None \\
\hline & 67 & M & Secondary & Head & None \\
\hline Ohno et al. (1994) & 62 & $\mathrm{~F}$ & Secondary & Tail & Spleen, stomachadrenal gland, kidney \\
\hline Abu-Hammour et al. (1996) & 61 & M & Secondary & Head & None \\
\hline Pääkkö et al. (1998) & 70 & M & Secondary & Head & None \\
\hline Hameed et al. (2000) & NA & NA & NA & Head & NA \\
\hline Rios et al. (2000) & 68 & M & Secondary & Head & None \\
\hline Hirata et al. (2002) & 33 & M & Primary & Head/tail & Maxillary sinus \\
\hline Balliu et al. (2003) & 32 & $\mathrm{~F}$ & Secondary & Head/body/tail & None \\
\hline Hiller et al. (2004) & 82 & $\mathrm{~F}$ & Secondary & Head & Sacral, skull base \\
\hline Coban et al. (2004) & 75 & M & Secondary & Head & None \\
\hline Deguchi et al. (2004) & 56 & M & Primary & Tail & Lymph nodes \\
\hline Kazama et al. (2005) & 70 & $\mathrm{~F}$ & Secondary & Head/body & Stomach, bladder \\
\hline Ali et al. (2007) & 64 & M & Secondary & Head & Chest wall \\
\hline Atiq et al. (2009) & 49 & $\mathrm{~F}$ & Secondary & Body & None \\
\hline Gupta et al. (2009) & 52 & M & Secondary & Head & Jejunum \\
\hline Spiegel et al. (2009) & 37 & M & Secondary & Head/body & None \\
\hline Leake et al. (2009) & 46 & M & Secondary & Head & None \\
\hline Wei et al. (2009) & 53 & $\mathrm{~F}$ & Primary & Head & Left shoulder \\
\hline Annibali et al. (2009) & 56 & M & Secondary & Head & None \\
\hline Padda et al. (2010) & 75 & M & Secondary & Head/proximal body & Stomach \\
\hline Coss et al. (2010) & 74 & M & Secondary & Head & None \\
\hline Artifon et al. (2010) & 57 & M & Secondary & Head & None \\
\hline Padda et al. (2010) & 75 & M & Secondary & Head & Stomach \\
\hline Pinto-Marques et al. (2010) & 64 & $\mathrm{~F}$ & Secondary & Head & None \\
\hline
\end{tabular}

$M$ male, $F$ female, $N A$ not available 
Table 2 Pancreatic location of the mass(es), clinical manifestations and treatment

\begin{tabular}{|c|c|c|c|}
\hline Cases & Pancreatic site & Clinical manifestations & Treatment \\
\hline Hefferman (1947) & Head & Duodenum & NA \\
\hline Richards et al. (1958) & Head & NA & NA \\
\hline Doutre et al. (1976) & Head & NA & NA \\
\hline Simon et al. (1978) & Head & Obstructive jaundice & RT \\
\hline Rice et al. (1981) & Head & Obstructive jaundice & NA \\
\hline Bell et al. (1982) & Head/Body & Obstructive jaundice & RT \\
\hline Twomey et al. (1983) & Head & Obstructive jaundice & RT \\
\hline Borgia et al. (1984) & Head & Obstructive jaundice & $\mathrm{RT}$ \\
\hline Helenon et al. (1984) & Head & Obstructive jaundice & RT \\
\hline Jaubert et al. (1985) & Head & Obstructive jaundice & Surgery \\
\hline Gorg et al. (1985) & Head & Obstructive jaundice & RT \\
\hline Mitchell et al. (1985) & Head & Obstructive jaundice & RT \\
\hline Speelberg et al. (1985) & Head & Obstructive jaundice & NA \\
\hline Zafaranloo et al. (1986) & Head & Obstructive jaundice & RT \\
\hline Scheinman et al. (1987) & Head/body/tail & Obstructive jaundice & $\mathrm{RT}+$ surgery \\
\hline Akiyama et al. (1988) & Head & Obstructive jaundice & RT \\
\hline Fukuya et al. (1989) & Head & Obstructive jaundice & RT \\
\hline Wilson et al. (1989) & Head & Abdominal pain, nausea & RT \\
\hline Brichon et al. (1989) & NA & NA & NA \\
\hline Hamamoto et al. (1990) & Head & Obstructive jaundice & Chemo \\
\hline Fischer et al. (1991) & Head & Obstructive jaundice & RT \\
\hline Davidson et al. (1993) & NA & NA & NA \\
\hline Olson et al. (1993) & $\operatorname{Head}(2 \mathrm{~L})$ & Obstructive jaundice & $\mathrm{RT}+$ chemo \\
\hline Fautrel et al. (1993) & Head & Obstructive jaundice & $\mathrm{RT}+$ surgery \\
\hline Tanaka et al. (1993) & Tail & Abdominal pain & Chemo+surgery \\
\hline \multirow[t]{2}{*}{ Dodd et al. (1994) } & Head & Obstructive jaundice & NA \\
\hline & Head & Obstructive jaundice & NA \\
\hline Ohno et al. (1994) & Tail & Pancreatitis & Chemo \\
\hline Abu-Hammour et al. (1996) & Head & Obstructive jaundice & RT \\
\hline Pääkkö et al. (1998) & Head & Obstructive jaundice & NA \\
\hline Hameed et al. (2000) & Head & Obstructive jaundice & NA \\
\hline Rios et al. (2000) & Head & Obstructive jaundice & $\mathrm{RT}+$ chemo \\
\hline Hirata et al. (2002) & Head/tail (2L) & Abdominal pain & RT \\
\hline Balliu et al. (2003) & Head/body/tail & Obstructive jaundice & Surgery \\
\hline Hiller et al. (2004) & Head & Nausea & RT \\
\hline Coban et al. (2004) & Head & Obstructive jaundice & RT \\
\hline Deguchi et al. (2004) & Tail & NA & Surgery (distal pancreatectomy \\
\hline Kazama et al. (2005) & Head/Body & Obstructive jaundice, abdominal pain & $\mathrm{RT}+$ chemo \\
\hline Ali et al. (2007) & Head & Obstructive jaundice & RT \\
\hline Atiq et al. (2009) & Body & Pancreatitis, GI bleeding & $\mathrm{Chemo} \rightarrow \mathrm{HSCT}$ \\
\hline Gupta et al. (2009) & Head & Obstructive jaundice & NA \\
\hline Spiegel et al. (2009) & Head/body & Obstructive jaundice, abdominal pain & $\mathrm{Chemo} \rightarrow \mathrm{HSCT}$ \\
\hline Leake et al. (2009) & Head & Obstructive jaundice, back pain, GI bleeding & None \\
\hline Wei et al. (2009) & Head & Obstructive jaundice & Chemo $\rightarrow$ Bortezomib \\
\hline Annibali et al. (2009) & Head & Obstructive jaundice, abdominal pain & Chemo \\
\hline Padda et al. (2010) & Head/proximal body & Obstructive jaundice & RT \\
\hline Coss et al. (2010) & Head & Obstructive jaundice & $\mathrm{RT}+$ surgery \\
\hline Artifon et al. (2010) & Head & Obstructive jaundice & Chemo \\
\hline Padda et al. (2010) & Head & Obstructive jaundice & RT \\
\hline Pinto-Marques et al. (2010) & Head & Asymptomatic & NA \\
\hline
\end{tabular}

$N A$ not available/not stated, $R T$ radiotherapy, Chemo chemotherapy, HSCT haematopoietic stem cell transplantation 
a

Pancreatic location of the plasmacytoma

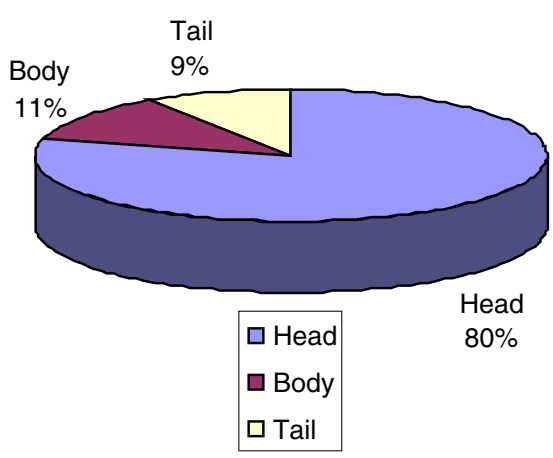

b

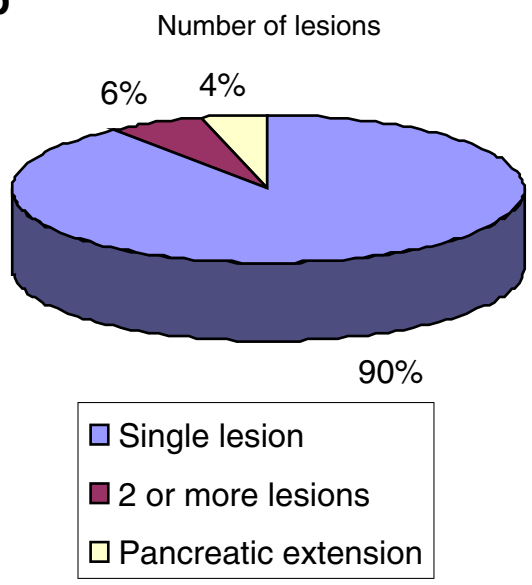

Fig. 1 a Pancreatic location of the EMP. b Number of pancreatic lesions

\section{Clinical Manifestations}

Symptoms from pancreatic EMPs depend on the site of the tumour, tumour size, and compression and/or involvement of the surrounding structures. Since most of them occur in the pancreas head, obstructive jaundice is by far the commonest symptom followed by abdominal pain. Pancreatitis, gastrointestinal bleeding and nausea have also been described in cases where a bulky mass was present. Rare cases detected in the early course of the disease are asymptomatic (Fig. 2).

\section{Diagnosis}

\section{Abdominal Imaging/Procedures}

Pancreatic involvement by $\mathrm{PCN}$ is rare and presents nonspecific radiologic features. Poorly differentiated pancreatic neoplasms and lymphoma may be difficult to differentiate from EMP. It is very difficult to radiologically differentiate EMP of the pancreas from other pancreatic tumours, especially those which show enhancement with intravenous contrast such as endocrine cell tumours and acinar cell neoplasms. Although it cannot make the diagnosis, imaging plays a key role since it identifies the location of the lesion and guides the biopsy.

\section{Transcutaneous Ultrasonography}

Transcutaneous ultrasonography (TUS) is very useful as an initial screening test in evaluating patients who present with possible obstructive jaundice. By helping detect intrahepatic or extrahepatic bile duct dilation, abdominal ultrasonography can rapidly and accurately assess whether or not a patient has biliary obstruction. Although less expensive and generally more readily available than computed tomography (CT) scanning, TUS has less utility than CT scanning because the pancreas is often obscured by overlying gas from the stomach, duodenum, and colon and the depth of the pancreas from the abdominal wall limits TUS imaging to lower frequency $(2-5 \mathrm{MHz})$; thus, a lowerresolution ultrasonographic image is obtained. Therefore, TUS can help detect only $60-70 \%$ of pancreatic masses, and similar to CT scanning, more than $40 \%$ of the lesions smaller than $3 \mathrm{~cm}$ are missed. On TUS, pancreatic infiltration by EMP has been described as a heterogeneous focal mass most often located in the head of the pancreas that is hypoechoic relative to the normal parenchyma and shows fine internal echoes $[21,42]$.

\section{Endoscopic Ultrasonography}

Endoscopic ultrasonography (EUS) has a proven record for staging pancreatic cancer and for cytological evaluation. This technique has increasingly been used to obtain

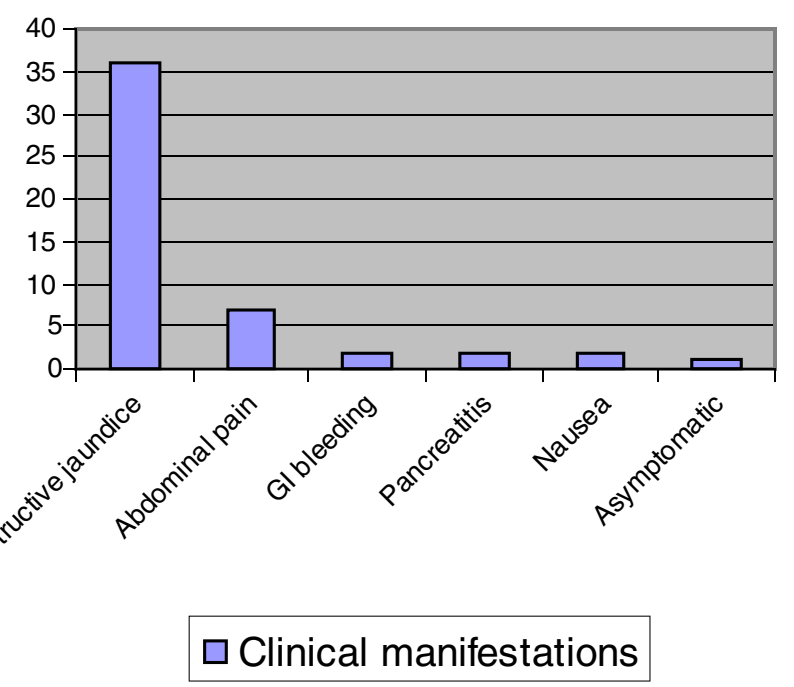

Fig. 2 Clinical manifestations 
material by fine-needle aspiration. EUS obviates the physical limitations of TUS by placing a high-frequency ultrasonographic transducer on an endoscope, which is then positioned in the stomach or duodenum endoscopically to help visualize the head, body and tail of the pancreas. Because of the proximity of the pancreas to the EUS transducer, high-frequency ultrasonography $(7.5-12 \mathrm{MHz})$ can be used to produce very high-resolution (submillimetres) images. Where expert EUS is available, it has been proven to be the most sensitive and specific diagnostic test for pancreatic cancer. EUS has detection rates of $99-100 \%$ for all pancreatic carcinomas, including those smaller than $3 \mathrm{~cm}$. A negative endoscopic ultrasound is nearly $100 \%$ specific at ruling out the presence of a pancreatic neoplasm. However, it is very operator-dependent, and as a result, its value varies widely with locally available expertise [49, 50, 54, 57].

\section{Computed Tomography Scan}

Because of its ubiquitous availability and ability to image the whole abdomen and pelvis, CT scan is the ideal method for assessing whether patients demonstrate pancreatic masses. CT scan may be particularly useful in patients who are not jaundiced and in those in whom intestinal gas interferes with US. CT scans with multiple detectors and dual- or triple-phase contrast enhancement have significantly improved the sensitivity and specificity of abdominal CT findings. When lesions are visible, CT scanning can also be used to direct fine-needle aspiration of pancreatic masses. However, small tumours can still be missed even with the most advanced CT scanning currently available. The CT appearance of pancreatic EMP is well established and is typically described as a multilobular homogenous solid tumour that is hypodense as compared to the pancreatic parenchyma. Diffuse enlargement of the pancreatic gland has been cited in only a few cases, and the contrast enhancement has been described as homogeneous or heterogeneous However, these CT features are not specific since they resemble typical findings in other pancreatic neoplasms, including carcinoma, islet cell tumours, lymphoma and metastases $[15,21,24,27$, 42, 46, 59-63].

\section{Magnetic Resonance Imaging}

The role of MRI in pancreatic cancer has been less well studied than the role of CT scanning. It does not appear to be superior to spiral CT scanning. Some authors suggest that this modality may be better in demonstrating pancreatic infiltration than CT. MRI imaging features of EMP included pancreatic enlargement and a lobulated contour. On fat- suppressed T1-weighted MR images, the signal intensity of the pancreas is less than that of the liver, whereas on T2weighted images, it is higher. Pancreatic contrast enhancement is heterogeneous, but dynamic MR imaging was never performed [38, 42, 64].

\section{Endoscopic Retrograde Cholangiopancreatography}

Endoscopic retrograde cholangiopancreatography (ERCP) is most useful for patients in whom CT or US does not reveal a mass lesion within the pancreas and in those in whom the differential diagnosis includes chronic pancreatitis. ERCP is highly sensitive at detecting pancreatic and/or biliary ductal abnormalities. However, the changes observed on ERCP are not always highly specific. Besides, it is more invasive than the other diagnostic imaging modalities and also carries a $5-10 \%$ risk of significant complications with the procedure. ERCP findings provide only limited staging information, but ERCP does have the advantage of allowing for therapeutic palliation of obstructive jaundice with either a plastic or metal biliary stent. ERCP may demonstrate smooth strictures, dilated common bile duct and proximal pancreatic duct. The demonstration of a smooth stenosis of the biliary tree is more suggestive of an EMP than adenocarcinoma where irregular stenosis is classical $[37,41,65]$.

\section{Positron Emission Tomography Scanning}

Positron emission tomography (PET) does not seem to offer additional benefits to high-quality $\mathrm{CT}$ scan, and its role to detect EMP has not been evaluated yet. PET scanning combined with simultaneous CT (PET-CT) suggests that PET-CT is more sensitive than conventional imaging for the detection of pancreatic cancer [66]. Patients suspected of having a pancreatic mass are initially studied with abdominal TUS and/or spiral CT scanning. If a mass is detectable, a CT- or TUS-guided biopsy of the mass follows. EUS plays a central role in the definitive diagnosis, so if available, high-quality EUS-guided fine-needle aspiration (EUS-FNA) is done to confirm the disease cytologically. All these imaging techniques are helpful in demonstrating the pancreatic mass, but are not able to determine its exact nature. Only immunohistochemical or flow cytometry analysis of the lesion obtained by laparotomy or by image-guided percutaneous biopsy or EUS-FNA can give the final result. Nowadays, it is suggested that after imaging/echographic finding, a percutaneous biopsy or a EUS-FNA should be performed, eliminating exploratory laparotomy, a high-risk procedure in this type of patient. EUS-FNA has been proven to be the most effective 
means for making a definitive cytologic diagnosis of a pancreatic mass since a cytologic diagnosis can be made in $85-95 \%$ of patients.

\section{Histopathological Findings/Immunohistochemistry}

Because of its scarcity and the cytomorphologic similarity between plasma cells and endocrine cells, EMP of the pancreas may be confused with neuroendocrine (islet cell) tumours of the pancreas. Immunohistochemical staining for light chain and/or neuroendocrine markers will prevent diagnostic error when interpreting plasmacytoid neoplasms of any site susceptible to endocrine tumours, including the pancreas.

In EMP, the plasma cells have round to oval eccentric nuclei, nuclear membrane irregularity, occasional prominent nucleoli and a fine to coarsely clumped chromatin pattern. The cytoplasm is abundant and basophilic, with a perinuclear clear zone. Immunohistochemical study of a biopsy specimen of an EMP is fundamental as it shows atypical plasma cells. The cells express strong CD38, CD138 and light-chain restriction.

CD20, a B cell marker, is not expressed by the malignant cells, and this excludes the possibility of a diagnosis of a marginal zone B cell lymphoma of mucosa-associated lymphoid tissue lymphoma. CD56 is aberrantly expressed in $67-79 \%$ cases, which aids in differentiating EMP from lymphomas.

\section{Cytogenetics and Fluorescent In Situ Hybridization}

Genetic abnormalities are detected in about $33 \%$ of PCM, and fluorescent in situ hybridization (FISH) increases the proportion with chromosomal abnormalities to more than $90 \%$. Cytogenetics have prognostic importance, and the unfavourable cytogenetic risk group has a shorter median survival than those without. The unfavourable cytogenetic risk includes deletion of chromosome 13 or aneuploidy by classical cytogenetics, chromosome translocations like $\mathrm{t}$ $(4 ; 14)$ or $\mathrm{t}(14 ; 16)$ or $\mathrm{t}(14 ; 20)$, and the deletion of $17 \mathrm{p} 13$ by FISH and has a shorter median survival than those with a more favourable risk with the absence of unfavourable genetics or have hyperdiploidy, $\mathrm{t}(11 ; 14)$ or $\mathrm{t}(6 ; 14)$ by FISH [2].

\section{Bone Marrow Aspiration}

A bone marrow (BM) sample is essential to clarify whether the EMP occurs in the context of a PCM. Concurrent presence of clonal plasma cells in BM and EMP makes the diagnosis of PCM, and the EMP is regarded as secondary. This obviously has therapeutic relevance since the management is more complex, requiring a combination of diverse modalities of treatment.

\section{Differential Diagnosis}

The differential diagnosis of a pancreatic EMP includes adenocarcinoma, focal pancreatitis, lymphoma, pancreatic neuroendocrine tumours and metastasic disease.

- Adenocarcinoma of the ductal epithelium, a hypovascular lesion that often $(66 \%)$ occurs in the pancreatic head, has a slight male predominance $(60 \%)$ and is more common in Blacks than Caucasians. These represent approximately $85 \%$ of pancreatic masses. The cells present a fragile, basophilic, granular cytoplasm and nuclei with often prominent nucleoli; the slide background shows distinctive finely vacuolated or foamy material derived from tumour cell cytoplasm which contrasts with the plasma cells' high nuclear/cytoplasmic ratio, blue cytoplasm, eccentric nucleus, perinuclear pale zone resembling a halo and a prominent nucleoli.

- Islet cell/endocrine tumour is hypervascular and may have malignant potential. These represent approximately $10 \%$ of pancreatic masses. Islet cell/endocrine tumour demonstrates relatively small uniform neoplastic cells with a well-preserved rim of granular-appearing cytoplasm; the nuclei are most often eccentrically placed within the cell cytoplasm, giving a plasmacytoid appearance, with finely granular and evenly distributed chromatin. Immunohistochemical staining for light chain and/or neuroendocrine markers is crucial. Distinctive cytomorphology, immunoperoxidase characteristics and negative flow cytometry analysis help differentiate between neuroendocrine tumours and plasmacytoma.

- Primary or secondary lymphoma is rare but not uncommonly seen at autopsy in cases of non-Hodgkin's lymphoma (one third of cases). At autopsy, it is difficult to distinguish whether a mass is primary or the result of tumour infiltration from peripancreatic nodes. Pancreatic lymphoma is often described as a large, homogeneous mass with extrapancreatic extension, with or without associated lymphadenopathy. Primary pancreatic lymphoma constitutes $0.5 \%$ of all pancreatic mass $[67,68]$.

- Focal/florid chronic pancreatitis could be differentiated from plasmacytomas due to the presence of calcifications and areas of necrosis [69].

- Metastasis is rare but can occur with melanoma as well as breast and bronchogenic carcinoma. Metastases to the pancreas are generally multiple and associated with known primaries, whilst plasmacytomas of the pancreas are in almost all cases single nodular lesions. 


\section{Treatment}

There appears to be no standardized treatment for extramedullary plasmacytomas of the pancreas. Surgery, radiotherapy and chemotherapy with haematopoietic stem cell transplantation have all been employed. For primary EMP, radiotherapy and/or surgery are sufficient. Systemic chemotherapy is required for secondary EMP.

\section{Radiotherapy}

Based on the documented radiation sensitivity of EMP, the treatment of choice is local radiotherapy (dose of at least $4.5 \mathrm{~Gy}$, depending on tumour size; the optimal dose for local control is 40-50 Gy, delivered over 4-6 weeks) [41]. The local control rate of radiotherapy (RT) can reach 90 $97 \%$, and the 5-year overall survival rate can be $57-61 \%$ $[70,71]$.

\section{Surgery}

Solitary plasmacytoma of the tail of the pancreas can also be managed by distal pancreatectomy in good surgical candidates. Patients with upper aerodigestive tract EMP who had combined surgery and radiation therapy had a higher median overall survival (25 years) than surgical intervention alone (median 13 years) or only radiation therapy (median 12 years). However, in cases on non-upper aerodigestive tract EMP, it appears that no statistical difference in survival is observed [6]. In the literature, cases with multifocal or bulky pancreatic involvement have been managed with combined RT plus surgery or, in selected cases of isolated pancreatic tail mass, surgery alone (distal pancreatectomy) [20, 24, 33, 34, 42, 45, 56]. Surgical procedures, other than distal pancreatectomy for isolated pancreatic tail involvement, are not commonly performed owing to the often systemic nature of the disease and the radical nature of these surgical procedures. Unsuspected cases may undergo pancreatic resection typical for pancreatic lesions with subsequent identification of plasma cells [45].

\section{Chemotherapy and auto-HSCT}

Chemotherapeutic agents are commonly used, combined or not with radiotherapy particularly when plasmacytomas are secondary in nature. In eligible patients, the standard of care of PCM is steroid-chemotherapy combinations followed by autologous haematopoietic stem cell transplantation (auto-HSCT). However, the optimal induction therapy prior to auto-HSCT is currently not known. Vincristine, doxorubicin (Adriamycin) and dexamethasone (VAD) had long been used as the standard induction chemotherapy, but has been replaced by the advent of novel drugs. Thalidomide (an immunomodulatory drug with major anti-angiogenic activity) plus dexamethasone resulted in a significantly higher response rate of $76 \%$ versus $52 \%$ in VAD arm [72-75]. Bortezomib is a proteasome inhibitor, PS-341. It induces apoptosis, reverses drug resistance of multiple myeloma cells and affects their microenvironment by blocking cytokine circuits, cell adhesion, and angiogenesis in vivo. Bortezomib presents a response rate of $27-38 \%$ and a 1-year overall survival rate of $80 \%$ in patients with refractory relapsed multiple myeloma and is also effective in multiple myeloma with extramedullary infiltration [76-78]. Four prospective randomized European studies have established that autoHSCT confers superior overall survival and/or event-free survival when compared with standard chemotherapy therapy [79-82]. It also results in a higher CR rate. Multiple studies have indicated that the best preparative regimen for autologous transplantation is melphalan $200 \mathrm{mg} / \mathrm{m}^{2}$. Comparison between a single with tandem transplants has clearly shown a superior outcome with tandem transplants. Patients who are not candidates for transplantation should be treated with combinations of cytotoxic drugs with the newer drugs, such as melphalan, thalidomide or lenalidomide or bortezomib, and dexamethasone [83-86]. Extramedullary relapses of MM after auto-HSCT are very resistant to conventional chemotherapy. The role of new drugs and the optimal treatment strategy in these cases remain to be defined.

\section{Prognosis and Outcome}

Approximately $70 \%$ of patients with EMP remain free of disease at 10 years, whilst up to $30 \%$ develop frank PCM or multiple extramedullary tumours. Survival in these patients is related to the underlying systemic illness. Consequently, the course for EMP not related to PCM is more favourable than that of PCM or solitary plasmacytoma of the bone. Life expectancy related to EMP of the pancreas has been quoted as 1 day to 6 years in the literature [12-58]. In EMP secondary to PCM, the prognosis is related to the underlying disease. Therefore, attempts to better identify subgroups of patients with distinct outcomes have led to the recognition of various prognostic factors. The serum level of $\beta 2$-Microglobulin is one of the most important prognostic factors in myeloma since it reflects tumour load and renal function. Other indicators of higher-risk patients include low serum albumin, elevated lactate dehydrogenase, high C-reactive protein, increased plasma cell proliferative activity, high degree of BM replacement, plasmablastic morphology and genetics. Two PCM staging systems are currently used. The Durie-Salmon myeloma 
staging system, which applies commonly available clinical parameters to predict plasma cell burden (low, intermediate, high) with a significant difference in survival between each of these three tumour mass stages [87], and an international staging system for PCM which provides a highly significant prognostic correlation using a combination of serum $\beta 2$-Microglobulin and albumin to define three stages with a median survival of 62,44 and 29 months, respectively [88].

\section{Conclusions}

Pancreatic involvement by $\mathrm{PCN}$ is extremely rare, comprising $<0.1 \%$ of all pancreatic masses. Among those $0.1 \%$, primary EMP is much less common than the EMP secondary to PCM. Therefore, in a patient with PCM or solitary plasmacytoma, the presence of a pancreatic mass should raise our attention for the possibility of a pancreatic plasmacytoma. However, an unrelated pancreatic mass, such as an adenocarcinoma, must be excluded. Percutaneous biopsy or EUS-FNA is a simple and effective way to establish the correct diagnosis of an EMP, but clonality must be proven by immunohistochemistry or immunophenotyping of the biopsy specimen. Standardized treatment for EMP of the pancreas is not defined yet. Owing to its uncommon nature, the comparative assessment of treatment modalities is not feasible. In the absence of such evidence, extrapolation from the treatment of PCM seems reasonable and has been shown to improve the extent of obstructive jaundice in these patients.

Conflict of interest The author declares no potential conflict of interest.

\section{References}

1. Saif MW. Primary pancreatic lymphomas. JOP. 2006;7:262-73.

2. Swerdlow SH, Campo E, Harry NL, et al., editors. WHO classification of tumours of haematopoietic and lymphoid tissues; 2008.

3. Tomita T. Amyloidosis of pancreatic islets in primary amyloidosis (AL type). Pathol Int. 2005;55:223-7.

4. Höppener JW, Nieuwenhuis MG, Vroom TM, Lips CJ. Islet amyloid and diabetes mellitus type 2. Ned Tijdschr Geneeskd. 2000;144:1995-2000.

5. Gandhi GY, Basu R, Dispenzieri A, Basu A, Montori VM, Brennan MD. Endocrinopathy in POEMS syndrome: the Mayo Clinic experience. Mayo Clin Proc. 2007;82:836-42.

6. Alexiou C, Kau RJ, Dietzfelbinger H, et al. Extramedullary plasmacytoma: tumour occurence and therapeutic concepts. Cancer. 1999;85:2305-14.

7. Jemal A, Siegel R, Ward E, Murray T, Xu J, Thun MJ. Cancer statistics, 2007. CA Cancer J Clin. 2007;57:43-66.
8. Ries LA, et al., editors. SEER Cancer Statistics Review, 19752001. National Cancer Institute, Bethesda, MD; 2004.

9. Anon. Criteria for the classification of monoclonal gammophaties, multiple myeloma and related disorders: a report of the International Myeloma Working Group. Br J Haematol. 2003;121:749-57.

10. Hefferman A. Plasmacytoma of pancreas and duodenum causing acute intestinal obstruction. Lancet. 1947;1:910.

11. Richards WG, Katzmann FS, Coleman FC. Extramedullary plasmacytoma arising in the head of the pancreas: report of a case. Cancer. 1958;11:649-52.

12. Doutre LP, Leger H, Bobois JP, Diard F. Extra skeletal plasmacytic sarcoma located in the pancreas. Chirurgie. 1976;102:130-5.

13. Simon TL, Rughani IK, Pierson DJ, Hebard DW. Multiple plasmacytomas with thoracic and biliary involvement. Arch Intern Med. 1978;138:1165-7.

14. Rice NT, Woodring JH, Mostowycz L, Purcell M. Pancreatic plasmacytoma: sonographic and computerized tomographic findings. J Clin Ultrasound. 1981;9:46-8.

15. Bell HG, David R, Shamsuddin AM. Extrahepatic biliary obstruction and liver failure secondary to myeloma of the pancreas. Hum Pathol. 1982;13:940-2.

16. Twomey BP, Katz D. Computed tomography in the diagnosis of extramedullary plasmacytoma. J Comput Tomogr. 1983;7:407-8.

17. Borgia G, Ciampi R, Nappa S, Vallone G, Iovinella V, Crowell J. Clinical and diagnostic considerations on a case of pancreatic plasmacytoma. Minerva Med. 1984;75:2839-42.

18. Borgia G, Ciampi R, Nappa S, Iovinella V, Crowell J. Pancreatic plasmacytoma: an unusual cause of obstructive jaundice. Arch Pathol Lab Med. 1984;108:773-4.

19. Helenon O, Bonnel D, Bigot JM, Carette MF, Pene F. Plasmacytoma of the head of the pancreas. Diagnosis by puncture aspiration guided by echography. Presse Med. 1984;13:2645.

20. Görg C, Schwerk W, Görg K, Pflüger KH, Havemann K. Extrahepatic biliary obstruction caused by infiltration of the pancreas by plasmacytoma. Klin Wochenschr. 1985;63:718-21.

21. Jaubert D, Hauteville D, Verdier M, et al. Plasmacytoma of the head of the pancreas: a rare cause of cholestatic jaundice. Gastroenterol Clin Biol. 1985;9:532-4.

22. Mitchell DG, Hill MC. Obstructive jaundice due to multiple myeloma of the pancreatic head: CT evaluation. J Comput Assist Tomogr. 1985;9:1118-9.

23. Speelberg B, Kluin PM, Punt K, Lips CJ. Non-secreting extramedullary plasmacytoma with late involvement of the pancreas causing obstructive jaundice. Neth J Med. 1985;28:291-94.

24. Zafaranloo S, Bryk D, Gerard PS. Obstructive jaundice secondary to multiple myeloma — a case report. Comput Radiol. 1986;10:197-200.

25. Scheiman J, Elta G, Francis I. Biliary obstruction secondary to an extramedullary plasmacytoma of the pancreas: confusion with pancreatitis on computed tomography. Pancreas. 1987;2:237-9.

26. Akiyama H, Krigel RL. Metastatic extramedullary plasmacytoma: a case report and review of the literature of a rare pseudocarcinoma. Am J Hematol. 1988;27:115-7.

27. Fukuya T, Yoshimitsu K, Kitagawa S, Murakami J, Masuda K, Nakamura K. Plasmacytoma of the pancreatic head. Gastrointest Radiol. 1989;14:226-8.

28. Wilson TE, Korobkin M, Francis IR. Pancreatic plasmacytoma: CT findings. AJR Am J Roentgenol. 1989;152:1227-8.

29. Brichon P, Solary E, Caillot D, Boussuge C, et al. Extramedullary pancreatic localization of myeloma. Ann Med Interne (Paris). $1989 ; 140: 421-2$.

30. Hamamoto K, Kosaka C, Takeno M, et al. Multiple myeloma causing obstructive jaundice by extramedullary plasmacytoma after Bence Jones protein loss - an autopsy case report. Rinsho Ketsueki. 1990;31:57-61.

31. Fischer A, Suhrland MJ, Vogl SE. Myeloma of the head of the pancreas. A case report Cancer. 1991;67:681-3. 
32. Davidson BS, Lee JE, Dodd LG, Dimopoulos MA, Evans DB. Extramedullary plasmacytoma of the pancreas. Am J Clin Oncol. 1993;16:363-8.

33. Olson MC, Kalbhen CL, Posniak HV. Pancreatic plasmacytomas in a patient with multiple myeloma: $\mathrm{CT}$ and ultrasound findings. Abdom Imaging. 1993;18:323-4.

34. Fautrel B, Marolleau JP, Charleux F, Brice P, Frija J, Gisselbrecht C. Pancreatic and hepatic plasmocytomas: an exceptional case. Nouv Rev Fr Hematol. 1993;35:125-8.

35. Tanaka Y, Samma S, Hayashi Y, et al. A case of retroperitoneal extramedullary plasmacytoma. Hinyokika Kiyo. 1993;39:639-43.

36. Ohno T, Saka Y, Horii J, et al. Aggressive transformation of an indolent myeloma with abdominal extramedullary plasmacytoma after 6-year period of observation. Rinsho Ketsueki. 1994;35:390-6.

37. Dodd LG, Evans DB, Symmans F, Katz RL. Fine-needle aspiration of pancreatic extramedullary plasmacytoma: possible confusion with islet cell tumor. Diagn Cytopathol. 1994;10:371-4.

38. Abu-Hammour AM, Venu RP, Etzkorn KP, Showel JL, Zaytsev PM, Brown RD. Common bile duct obstruction caused by multiple myeloma of the pancreas. Gastrointest Endosc. 1996;44:606-8.

39. Pääkkö E, Autio R, Lähde S. Plasmacytoma of the pancreas: CT and MRI appearance. Rofo. 1998;169:673-5.

40. Ríos A, Ramírez P, Majado MA, Parrilla P. Obstructive jaundice caused by pancreatic head tumor secondary to $\operatorname{IgG}$ multiple myeloma. Rev Esp Enferm Dig. 2000;92:475-6.

41. Hirata S, Yamaguchi K, Bandai S, Izumo A, Chijiiwa K, Tanaka M. Secondary extramedullary plasmacytoma involving the pancreas. J Hepatobiliary Pancreat Surg. 2002;9:111-5.

42. Balliu E, Casas JD, Barluenga E, Guasch I. Multifocal involvement of the pancreas in multiple myeloma: sonographic, CT, and MR imaging findings. AJR Am J Roentgenol. 2003;180:545-6.

43. Hiller N, Goitein O, Ashkenazi YJ. Plasmacytoma of the pancreas. Isr Med Assoc J. 2004;6:704-5.

44. Coban S, Koklu S, Ertugrul I, Kuzu I, Bahar K. Obstructive jaundice in a patient with multiple myeloma. J Gastroenterol Hepatol. 2004;19:837-8.

45. Deguchi Y, Nonaka A, Takeuchi E, Funaki N, Kono Y, Mizuta K. Primary pancreatic plasmacytoma. Am J Clin Oncol. 2004;27:247-9.

46. Kazama T, Ng CS, Giralt SA. Multiphasic CT and MRI appearances of extramedullary multiple myeloma involving the stomach, pancreas, and bladder. Clin Imaging. 2005;29:263-5.

47. Ali R, Ozkalemkas F, Ozcelik T, et al. Extramedullary plasmacytoma involving the abdominal vessels and pancreas. Dig Dis Sci. 2007;52:3199-201.

48. Hameed A, Ryan M, Kamel D, Vusirikala M. Plasmacytoma of the pancreas and pelvis: a case report. Lab Hematol. 2008;14:10-1.

49. Atiq M, Ali SA, Dang S, et al. Pancreatic plasmacytoma presenting as variceal hemorrhage: life threatening complication of a rare entity. JOP. 2009;10:187-8.

50. Spiegel A, Patel R, Pais S. Obstructive jaundice secondary to a pancreatic plasmacytoma. Clin Gastroenterol Hepatol. 2009;7:A32.

51. Gupta P, Rice GD, Abraham K, Ghole V, Ketkar M. Extramedullary plasmacytoma of the pancreas and jejunum. Clin Imaging. 2009;33:240-3.

52. Leake PA, Coard KC, Plummer JM. Extramedullary plasmacytoma of the pancreas as an uncommon cause of obstructive jaundice: a case report. J Med Case Reports. 2009;3:8785.

53. Wei JY, Tong HY, Zhu WF, et al. Bortezomib in treatment of extramedullary plasmacytoma of the pancreas. Hepatobiliary Pancreat Dis Int. 2009;8:329-31.

54. Annibali O, Marchesi F, Petrucci MT, Tirindelli MC, Avvisati G. Relapse of IgA lambda multiple myeloma presenting as obstructive jaundice and abdominal pain. Onkologie. 2009;32:119-21.

55. Padda MS, Milless T, Adeniran AJ, Mahooti S, Aslanian HR. Pancreatic and gastric plasmacytoma presenting with obstructive jaundice, diagnosed with endoscopic ultrasound-guided fine needle aspiration. Case Rep Gastroenterol. 2010;4:410-5.

56. Coss A, Zhou C, Byrne MF, Weiss AA. Relapse of multiple myeloma presenting with biliary obstruction. Can J Gastroenterol. 2010;24:237-8

57. Artifon E, Okawa L, Baba E, Moura E, Sakai P, Savides T. Diagnosis of pancreatic plasmacytoma by endoscopic ultrasound-fine needle aspiration. Rev Gastroenterol Mex. 2010;75:357-9.

58. Pinto-Marques P, Martins C, Mendonça E, Castro H, Serra D. Pancreatic head mass of unusual etiology: multiple myeloma diagnosed by endoscopic ultrasound-guided fine needle aspiration. Endoscopy. 2010;42 Suppl 2:E263-4.

59. Gritzmann N, Macheiner P, Hollerweger A, Hübner E. CT in the differentiation of pancreatic neoplasms - progress report. Dig Dis. 2004;22:6-17.

60. Kauhanen SP, Komar G, Seppänen MP, et al. A prospective diagnostic accuracy study of ${ }^{18} \mathrm{~F}$-fluorodeoxyglucose positron emission tomography/computed tomography, multidetector row computed tomography, and magnetic resonance imaging in primary diagnosis and staging of pancreatic cancer. Ann Surg. 2009;250:957-63.

61. Farma JM, Santillan AA, Melis M, et al. PET/CT fusion scan enhances CT staging in patients with pancreatic neoplasms. Ann Surg Oncol. 2008;15:2465-71.

62. Itani KM, Taylor TV, Green LK. Needle biopsy for suspicious lesions of the head of the pancreas: pitfalls and implications for therapy. J Gastrointest Surg. 1997;1:337-41

63. Turner BG, Cizginer S, Agarwal D, Yang J, Pitman MB, Brugge WR. Diagnosis of pancreatic neoplasia with EUS and FNA: a report of accuracy. Gastrointest Endosc. 2010;71:91-8.

64. Sheridan MB, Ward J, Guthrie JA, et al. Dynamic contrastenhanced MR imaging and dual-phase helical CT in the preoperative assessment of suspected pancreatic cancer: a comparative study with receiver operating characteristic analysis. AJR Am J Roentgenol. 1999;173:583-90.

65. Adamek HE, Albert J, Breer H, Weitz M, Schilling D, Riemann JF. Pancreatic cancer detection with magnetic resonance cholangiopancreatography and endoscopic retrograde cholangiopancreatography: a prospective controlled study. Lancet. 2000;356:190-3.

66. Yamaguchi K, Chijiwa K, Shimizu S, Yokohata K, Morisaki T, Tanaka M. Comparison of endoscopic retrograde and magnetic resonance cholangiopancreatography in the surgical diagnosis of pancreatic diseases. Am J Surg. 1998;175:203-8.

67. Islam $\mathrm{S}$, Callery MP. Primary pancreatic lymphoma - a diagnosis to remember. Surgery. 2001;129:380-3.

68. Salvatore JR, Cooper B, Shah I, Kummet T. Primary pancreatic lymphoma: a case report, literature review, and proposal for nomenclature. Med Oncol. 2000;17:237-47.

69. van Gulik TM, Moojen TM, van Geenen R, Rauws EA, Obertop H, Gouma DJ. Differential diagnosis of focal pancreatitis and pancreatic cancer. Ann Oncol. 1999;10 Suppl 4:85-8.

70. Mayr NA, Wen BC, Hussey DH, et al. The role of radiation therapy in the treatment of solitary plasmacytomas. Radiother Oncol. 1990;17:293-303.

71. Jyothirmayi R, Gangadharan VP, Nair MK, Rajan B. Radiotherapy in the treatment of solitary plasmacytoma. Br J Radiol. 1997;70:511-6.

72. Kumar S, Rajkumar SV. Thalidomide and dexamethasone: therapy for multiple myeloma. Expert Rev Anticancer Ther. 2005;5:759-66.

73. Rajkumar SV, Hayman S, Gertz MA, et al. Combination therapy with thalidomide plus dexamethasone for newly diagnosed myeloma. J Clin Oncol. 2002;20:4319.

74. Wang M, Weber D, Delasalle K, et al. Thalidomide-dexamethasone as primary therapy for advanced multiple myeloma. Am J Hematol. 2005;79:194.

75. Cavo M, Zamagni E, Tosi P, et al. Superiority of thalidomide and dexamethasone over vincristine-doxorubicin-dexamethasone 
(VAD) as primary therapy in preparation for autologous transplantation for multiple myeloma. Blood. 2005;106:35.

76. Paubelle E, Coppo P, Garderet L, et al. Complete remission with bortezomib on plasmocytomas in an end-stage patient with refractorymultiple myeloma who failed all other therapies includinghematopoietic stem cell transplantation: possibleenhancement of graft-vs-tumor effect. Leukemia. 2005;19:1702-4.

77. Krauth MT, Bankier A, Valent P, Kalhs P, Drach J. Sustained remission including marked regression of a paravertebral plasmacytoma in a patient with heavilypretreated, relapsed multiple myeloma after treatment with bortezomib. Leuk Res. 2005;29:1473-7.

78. Laura R, Cibeira MT, Uriburu C, et al. Bortezomib: an effective agent in extramedullary disease in multiple myeloma. Eur JHaematol. 2006;76:405-8.

79. Attal M, Harousseau JL, Stoppa AM, et al. A prospective, randomized trial of autologous bone marrow transplantation and chemotherapy in multiple myeloma. Intergroupe Francais du Myelome. N Engl J Med. 1996;335:91.

80. Fermand JP, Katsahian S, Divine M, et al. High-dose therapy and autologous blood stem-cell transplantation compared with conventional treatment in myeloma patients aged 55 to 65 years: long-term results of a randomized control trial from the Group Myelome-Autogreffe. J Clin Oncol. 2005;23:9227.

81. Child JA, Morgan GJ, Davies FE, et al. High-dose chemotherapy with hematopoietic stem-cell rescue for multiple myeloma. N Engl J Med. 2003;348:1875.
82. Palumbo A, Bringhen S, Petrucci MT, et al. Intermediate-dose melphalan improves survival of myeloma patients aged 50 to 70 : results of a randomized controlled trial. Blood. 2004;104:3052.

83. Facon T, Mary JY, Hulin C, et al. Melphalan and prednisone plus thalidomide versus melphalan and prednisone alone or reducedintensity autologous stem cell transplantation in elderly patients with multiple myeloma (IFM 99-06): a randomised trial. Lancet. 2007;370:1209.

84. Hulin C, Facon T, Rodon P, et al. Efficacy of melphalan and prednisone plus thalidomide in patients older than 75 years with newly diagnosed multiple myeloma: IFM 01/01 trial. J Clin Oncol. 2009;27:3664.

85. Palumbo A, Bringhen $\mathrm{S}$, Caravita $\mathrm{T}$, et al. Oral melphalan and prednisone chemotherapy plus thalidomide compared with melphalan and prednisone alone in elderly patients with multiple myeloma: randomised controlled trial. Lancet. 2006;367:825.

86. Mateos MV, Hernandez JM, Hernandez MT, et al. Bortezomib plus melphalan and prednisone in elderly untreated patients with multiple myeloma: results of a multicenter phase $1 / 2$ study. Blood. 2006;108:2165.

87. Durue BG, Salmon SE. A clinical staging system for multiple myeloma. Correlation of measured myeloma cell mass with presenting clinical features, response to treatment and survival. Cancer. 1975;36:842-54.

88. Greipp PR, San Miguel J, Durie BG, et al. International staging system for multiple myeloma. J Clin Oncol. 2005;23:3412-20. 